\title{
Somali, Latino and Hmong parents' perceptions and approaches about raising healthy-weight children: a community-based participatory research study
}

\author{
Chrisa Arcan ${ }^{1, *}$, Kathleen A Culhane-Pera ${ }^{2}$, Shannon Pergament ${ }^{2}$, Maira Rosas-Lee ${ }^{2}$ and \\ Mai Bao Xiong ${ }^{2}$ \\ ${ }^{1}$ Family, Population, and Preventive Medicine, Medical School, HSC L3, Room 086, Stony Brook, NY 1 1794-8461, \\ USA: ${ }^{2}$ Somali, Latino, and Hmong Partnership for Health and Wellness (SoLaHmo), West Side Community Health \\ Services, Saint Paul, MN, USA
}

Submitted 22 November 2016: Final revision received 2 June 2017: Accepted 8 June 2017: First published online 14 August 2017

\begin{abstract}
Objective: Immigrants in the USA are confronted with health disparities, including childhood obesity and obesity-related chronic diseases. We aimed to identify perceptions of childhood body weight, approaches to raising healthy children and desires for supportive programmes of Somali, Latino and Hmong (SLM) parents in the Twin Cities, Minnesota, USA.

Design: Using community-based participatory research, ten focus groups (FG) were conducted with sixty-seven parents ( $n 28$ Somali, three FG; $n 19$ Latino, four FG; $n 20$ Hmong, three FG) of 3-12-year-old children in their native language. Demographic information was collected.

Results: SLM parents perceived that health is not necessarily weight-based; childhood obesity is caused by overeating, eating unhealthy foods and sedentary activities; traditional foods are generally healthy while American foods are generally unhealthy; and healthy children are inherently physically active. Parents identified their goals as feeding children so they would be healthy and happy, helping them be active and safe, and teaching them to cook traditional foods to be self-sufficient and maintain their cultural identity. Parents were challenged by children's unhealthy food and sedentary preferences, their own uncertainties about healthy foods and behaviours, and structural factors. Parents thought interventions could help them with these challenges, including information about healthy foods, age-appropriate portion sizes, safe places to be active and strategies tailored to their cultural norms. Conclusions: SLM parents are trying to raise healthy-weight children based on their understanding of children's health, weight, diet and physical activity, while dealing with social, economic and environmental challenges and trying to maintain cultural identity and traditions.
\end{abstract}

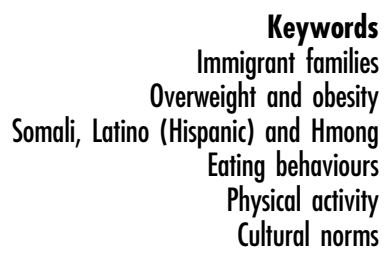

In the USA, immigrant groups are the fastest-growing population segment, comprising $13 \%$ of the total population, with 53\% from Latin America, 28\% from Asia and $4 \%$ from Africa $^{(1,2)}$. Immigrant communities are disproportionately confronted with health disparities including childhood obesity and obesity-related chronic diseases ${ }^{(3-5)}$. According to national data, Hispanic youth have higher rates of overweight or obesity than their White counterparts $^{(6)}$. Similarly, $16.7 \%$ of $2-5$-year-old Latino children are obese compared with $3.5 \%$ of Whites ${ }^{(7)}$. In Minnesota the rate of overweight/obesity is also higher among Latino, Somali and Hmong adolescents compared with Whites ${ }^{(8)}$.

Although newly arrived immigrants in the USA are healthier and have better weight status than their US-born counterparts $^{(9)}$, their risk for obesity ${ }^{(10)}$ and other chronic diseases $^{(11-13)}$ increases with longer time in the USA. Immigrant families face stressors stemming from resettlement and adjustment in the host country ${ }^{(14)}$, including financial realities, language differences, time constraints ${ }^{(15,16)}$, structural issues such as neighbourhood safety ${ }^{(17)}$, as well as new weather patterns ${ }^{(18-20)}$. Indeed, several studies of immigrants' health have shown that changes in lifestyle behaviours, such as change in diet quality and physical activity (PA), may be contributing to increase in weight, increase in incidence of chronic diseases and decrease in immigrants' perception of their health status ${ }^{(21-23)}$.

Families are essential agents of change providing a home environment that supports behaviours that influence 
weight $^{(24-27)}$. Important aspects of the home food environment, such as home food availability, family meal frequency, food preparation, parent role modelling and parent's encouragement for healthy eating, have been associated with weight-related dietary behaviours among youth ${ }^{(28,29)}$. Most of the research exploring the home food environment in immigrant families has involved Hispanics/Latinos ${ }^{(30-32)}$, with a paucity of data for other immigrant groups, such as Hmong and Somali ${ }^{(33-37)}$. However, there are limited data among immigrant families with younger-age children, including Latinos ${ }^{(30-32,34,38-40)}$. With the continuous arrival of immigrant groups and the ongoing changes in previously arrived people, further studies are needed to understand commonalities as well as differences in lifestyle behaviours of immigrant families with children. These identified issues could then inform programmes to support practices for healthy-weight children in immigrant populations.

According to the National Institutes of Health's Summit on The Science of Eliminating Health Disparities, health disparities research should build on strong community collaborations that promote community engagement ${ }^{(41)}$. Community-based participatory research (CBPR) is particularly appropriate for immigrant populations that are not routinely included in national studies, since it engages community partners as active participants in building knowledge in their unique communities ${ }^{(42-45)}$.

Following a CBPR approach, in the present study researchers and Somali, Latino and Hmong (SLH) community members sought to identify parents' perceptions of childhood body weight and obesity, barriers to and enablers of families' dietary and PA approaches, and suggestions for food and activity programmes that could support parents' efforts to raise healthy children. The long-term goal of the study was to inform the development of culturally appropriate programmes that would prevent obesity in SLH children.

\section{Methods}

The current CBPR study involved an academic-community partnership that included one academic researcher and eight community researchers (two clinic staff and six community members; two Somali, two Latino, two Hmong) with SoLaHmo Partnership for Health and Wellness (SoLaHmo), which is a community-participatory research programme of West Side Community Health Services, Inc. (West Side), in the Twin Cities, Minnesota, USA. All community members had CBPR and qualitative research training and experience and were involved in all phases of the project, including conception of the study, development of questions, administration, transcription, translation and analysis of focus groups, and interpretation of study findings.

\section{Study design and procedures}

Ten focus groups (three Somali, four Latino, three Hmong), were conducted with sixty-seven adults ( $n$ 28 Somali, $n 19$ Latino, $n 20$ Hmong; 81\% women) who were primary caregivers of at least one child aged 3-12 years (Table 1).

Table 1 Demographic characteristics of Somali, Latino and Hmong participants in the Twin Cities, Minnesota, USA, September 2011 through August 2012

\begin{tabular}{|c|c|c|c|c|c|c|c|c|}
\hline & \multicolumn{2}{|c|}{ Total (N 67) } & \multicolumn{2}{|c|}{ Somali ( $N 28)$} & \multicolumn{2}{|c|}{ Latino $(N 19)$} & \multicolumn{2}{|c|}{ Hmong (N 20) } \\
\hline & $n$ & $\%^{*}$ & $n$ & $\% *$ & $n$ & $\% *$ & $n$ & $\% *$ \\
\hline \multicolumn{9}{|l|}{ Gender } \\
\hline Women & 54 & $80 \cdot 6$ & 21 & $75 \cdot 0$ & 17 & 89.5 & 16 & $80 \cdot 0$ \\
\hline Men & 11 & $16 \cdot 4$ & 5 & $17 \cdot 9$ & 2 & $10 \cdot 5$ & 4 & $20 \cdot 0$ \\
\hline \multicolumn{9}{|l|}{ Age (years) } \\
\hline $18-30$ & 17 & $25 \cdot 3$ & 12 & $42 \cdot 8$ & 2 & 10.5 & 12 & $60 \cdot 0$ \\
\hline $31-50$ & 39 & 58.2 & 11 & 39.2 & 17 & 89.5 & 5 & $25 \cdot 0$ \\
\hline$>50$ & 10 & 14.9 & 5 & 17.9 & 0 & 0.0 & 3 & $15 \cdot 0$ \\
\hline \multicolumn{9}{|l|}{ Education } \\
\hline ESL only $/<H S$ & 38 & $56 \cdot 7$ & 22 & $78 \cdot 6$ & 19 & $100 \cdot 0$ & 13 & 65.0 \\
\hline HS & 17 & 25.4 & 5 & 17.9 & 0 & 0.0 & 2 & $10 \cdot 0$ \\
\hline College & 7 & 10.4 & 0 & 0.0 & 0 & 0.0 & 3 & $15 \cdot 0$ \\
\hline \multicolumn{9}{|c|}{ Lunch programme (school-age children) } \\
\hline Yes & 51 & $76 \cdot 1$ & 19 & 67.9 & 15 & 78.9 & 16 & 80.0 \\
\hline No & 7 & $10 \cdot 4$ & 2 & $7 \cdot 1$ & 3 & $15 \cdot 8$ & 2 & $10 \cdot 0$ \\
\hline Don't know & 4 & $6 \cdot 0$ & 4 & 14.3 & 0 & 0.0 & 0 & 0.0 \\
\hline \multicolumn{9}{|c|}{ WIC (children aged $<5$ years) } \\
\hline Yes & 44 & 65.7 & 17 & $60 \cdot 7$ & 12 & 63.2 & 15 & $75 \cdot 0$ \\
\hline No & 7 & $10 \cdot 4$ & 7 & $25 \cdot 0$ & 6 & 31.6 & 5 & $25 \cdot 0$ \\
\hline Don't know & 5 & 7.5 & 4 & $14 \cdot 3$ & 1 & $5 \cdot 3$ & 0 & 0.0 \\
\hline \multicolumn{9}{|l|}{ Birthplace } \\
\hline USA & 1 & 1.5 & 0 & 0.0 & 0 & 0.0 & 1 & $5 \cdot 0$ \\
\hline Outside USA & 66 & 98.5 & 28 & $100 \cdot 0$ & 19 & $100 \cdot 0$ & 19 & 95.0 \\
\hline \multicolumn{9}{|c|}{ Time in USA (years) } \\
\hline Mean & \multirow{2}{*}{\multicolumn{2}{|c|}{$\begin{array}{l}11.5 \\
1-26\end{array}$}} & \multicolumn{2}{|c|}{$7 \cdot 0$} & \multicolumn{2}{|c|}{$12 \cdot 0$} & \multicolumn{2}{|c|}{$17 \cdot 0$} \\
\hline Range & & & & & & & & \\
\hline
\end{tabular}

ESL, English as a second language; HS, high school; WIC, Special Supplemental Nutrition Program for Women, Infants, and Children.

*The values might not add up to $100 \%$ due to incidental missing data. 
With the exception of one participant, all others were born outside the USA; the number of years since their arrival to the USA differed for each ethnic community (Somalis: 1-12 years; Latinos: 2-20 years; Hmong: 6-26 years). Participants were recruited through telephoning patients at West Side and advertising at community centres and housing projects. (Note: we have used the word 'parents' throughout to designate all caregivers.)

The focus group questions were collectively developed by the entire group following extensive review of prior qualitative studies among immigrant populations. The focus groups lasted $1.5-2 \mathrm{~h}$ and took place at West Side, community centres or housing projects. They were conducted in a semi-structured manner in participants' native language or English by a trained native-speaking SoLaHmo community researcher and were supported by the academic researcher and two community researchers (one clinic staff and one native-speaking note taker). After the third focus group for each community, the research team decided a fourth group was necessary for the Latino community in order to obtain saturation; general focus group guidelines support aiming for saturation of ideas, which usually occurs with two to five groups per category of participants ${ }^{(46)}$. Prior to focus groups a brief demographic survey was completed by participants about their age, gender, education, birthplace, years lived in the USA, and their children's participation in the free or reduced-price school lunch and WIC (Special Supplemental Nutrition Program for Women, Infants, and Children) programmes.

The focus group questions elicited parents' views about healthy weight-children, causes of childhood obesity, barriers to and enablers of children eating and being physically active, aspects of their culture about healthy eating and being active that they wished to pass on to their children, and elements of potential programmes for children to achieve or maintain a healthy weight. Participants received \$US 20 for their participation. The study was approved by the Institutional Review Board of the University of Minnesota.

\section{Data coding and analysis}

A thematic analysis approach was utilized to analyse the transcripts with the full team, following CBPR principles $^{(47)}$. Initially, each community research team independently coded one transcript of its community's focus group, and then the entire research group met to identify a common coding tree. Guided by the common coding tree, each community team coded all of its community's focus group transcripts. In a reiterative fashion, the entire group met again to adjust the coding tree, and each team completed its focus group coding. Once all transcripts were coded, the entire group met again to identify themes and sub-themes ${ }^{(48,49)}$. The derived themes were then discussed and interpreted by each community, based on its cultural norms and beliefs. Similarities and differences among the three ethnic communities were collectively determined by all members.

\section{Results}

The overarching theme for all three cultural groups was 'parents' challenges in raising healthy-weight children in the USA'. SLH parents are trying to raise healthy-weight children based on their understanding of children's health, contributors to obesity, and importance of diet and PA, while dealing with social, economic and environmental challenges and trying to maintain their cultural identity and traditions. As there were more similarities than differences across the three ethnic groups, the common themes and sub-themes are presented first and any ethnic differences are subsequently specified. Tables $2-5$ display quotes that represent the larger set of participants' quotes (Table 2: parents' perceptions of healthy weight and causes of childhood obesity; Table 3: parents' goals, challenges and approaches for children to eat healthy foods; Table 4: parents' goals, challenges and strategies for children to be physically active; Table 5: parents' programmatic suggestions)

\section{Parents' perceptions of healthy weight and causes of childhood obesity}

Parent's perceptions of healthy-weight children

In general, parents from SLH communities stated that healthy children are happy and active, they sleep well and are not frequently sick. They described healthy children as having good appetites, high energy levels, colour in their faces or lips, and good muscle tone. In contrast, parents characterized unhealthy children as weak, becoming sick more often, not sleeping well, having poor appetites, pale faces, low energy levels and poor muscle tone, and perhaps being sad, lazy or depressed. Participants discussed that health is not necessarily weight-based, as children can be healthy at any weight, including weight extremes. Some Hmong and Somali parents said children in the middle of the weight range are likely to be healthier and stronger, with heavy and skinny children likely to be unhealthier and weaker, while a few Hmong parents said that fat children are healthy (Table 2).

\section{Causes of childhood obesity}

Participants from all three communities shared similar ideas about causes of childhood obesity. They stated that obese children in the USA are eating too much, or eating 'bad' foods (which they described as 'tasty', including salty, fatty and sweet foods) or eating 'American' foods (pizza, hamburgers, fast foods and junk food). Regarding PA, participants stated that obese children are not moving, are not exercising enough and are engaging in too many sedentary activities (i.e. watching too much television and playing too many video games). Participants also mentioned multiple environmental factors contributing to obesity, such as the low cost of unhealthy foods and the high cost of healthy foods, easy access to and availability of unhealthy foods, processed foods and chemicals 
Table 2 Somali (S), Latino (L) and Hmong (H) parents' perceptions of healthy weight and causes of childhood obesity, the Twin Cities, Minnesota, USA, September 2011 through August 2012

\section{Themes}

Parents' perceptions of

healthy-weight children

Summary/sub-themes

Health is not necessarily weight-based for younger children, as children can be healthy at either weight extremes

Parents' perceptions of causes of childhood obesity

Food: overeating, or eating 'tasty' foods that are salty, fatty and sweet, or American foods

Physical activity: children are not moving, are not exercising enough

Environment: cost of food, easy access and availability of food, processed foods, chemicals in foods, weather the fat melts away.

L. I think the

they're not too skinny or too fat:

$\mathrm{H}$ : 'If their muscles are tight, even if they're fat, they're healthy. They will not be sick If he is fat and his muscles are loose, then he will be very tired and not have much strength. You have to take him to go exercise so his muscles are tight and he has strength:'

S1: 'Junk food is the worst! If a child just eats food from outside he will become fat, and he isn't cooked natural food that was made in a pot, the child will become fat.'

S2: 'The mixed powdered juice that we add sugar.'

S3: 'Juice is a drink, people don't become fat from it.'

L1: 'Maybe the fast food because, being in this country ... the fast food is one of the main causes.'

L2: 'The amount of juice. Because juice is recommended, but it's the amount of juice that they drink'

H1: 'Parents like to feed their children to make them plump. They love their kids. They overfeed them. They don't feed only three meals a day. Our Hmong men and women at home, as long as our kids are hungry we generously feed them. They eat meats and rice only. They drink milk, eat whatever they want and eat as much as they want.'

$\mathrm{H} 2$ : 'The thing that makes kids big is ice cream and McDonalds ... [and] overeating. I have an older daughter that eats a lot like ... she is a lot bigger than the rest of the kids.'

S: 'That he doesn't exercise a lot ... A child that doesn't exercise - eating a lot of food - all that brings about the child getting fat.

L: 'Watch television for long periods of time and only eating without doing any type of exercise [causes obesity].'

H: '[l]n this country, you don't have a garden. You don't sweat. You eat and sit around. You don't have a chance to sweat. It can make you sick. Your body is not healthy.'

S: 'Children become fat if they have permission to go into the fridge so they can eat anything they want all night. That child will become fat and his food will be without control, so that he can eat whatever he wants.' L: 'I don't know what they inject in them [food]. I imagine it is hormones and I think that, the same way the little chickens are growing, we are also consuming those hormones that they're injecting in the little chickens. And I think that is also affecting the girls that gain weight."

$\mathrm{H}$ : "Another reason why they overeat is because in this country, when it gets cold, there are not enough places to be active. The kids are always home. The kids don't get a chance to jump around and be active or go anywhere.' 
Table 3 Somali (S), Latino (L) and Hmong (H) parents' goals, challenges and approaches for children to eat healthy foods, the Twin Cities, Minnesota, USA, September 2011 through August 2012

\begin{tabular}{ll}
\hline Themes & Summary/sub-themes \\
\hline $\begin{array}{c}\text { Parents' goals for children's } \\
\text { eating }\end{array}$ & $\begin{array}{c}\text { To provide healthy foods so their children are } \\
\text { healthy and happy }\end{array}$
\end{tabular}

Parent quotes

eating

healthy and happy

S1: 'Everything in our culture was healthy ... We drank camel milk, ate meat, wheat, and God didn't bring on earth any healthier dish.'

S2: 'The children are given vegetables for example - cooked and made at home - fruits for example. Food for example we give children as part of our culture - we eat pasta and we cook rice, soor [corn meal] - those are some of the things we mostly cook. We eat meat - fish, chicken and those are the things we feed our children.'

L1: 'I would like my daughters to hold on to the habits of not skipping any nutrients, eating three meals a day, and fruits between meals.

L2: 'My son, I just had a problem with him that he only wanted pizza, French fries, but right now, ultimately, he is eating [formal foods] like beans, which is another adventure because he doesn't eat ... because he doesn't get fat. I can 't get him to gain weight.'

$\mathrm{H}$ : 'I don't really know about others but for Hmong people to be healthy you have to eat things that are low in oils/fat, and things that do not have a lot of chemicals. This is something that is important.'

Teach children how to eat and prepare foods so they are healthy, and traditional foods so they maintain their cultural identity

S1: 'We want them [children] to make the foods that was cultural from their fathers and grandfathers, so that they know these were their grandfathers and it's their culture and heritage - we need that and we will teach it to them and they will, God willing, practise it.

S2: "Everything in our culture was healthy, and we want all that culture to be inherited by our children, that they take and keep our culture

L: 'To show them how to eat healthier because, I'm talking for myself, I am Mexican, but our culture, they don't show us how to eat. They show us how to make ourselves full, but not how to nutrition ourselves. Until now, that l've lived here in the US, now that I'm an adult, I have learned how to eat healthier because in our culture, that's how it is. $\mathrm{H} 1$ : 'When they are young, around 6 or 7 years old, when you cook you have to tell them to come watch and learn so that when you're not around they can cook for themselves. Have them learn what healthy foods are and what unhealthy foods are.

$\mathrm{H} 2$ : 'You have to teach girls and boys because ... when you're not around anymore, how will they survive? You have to teach them.'

Challenges to meeting Children's preferences for 'tasty' but 'unhealthy' parents' goals

$\mathrm{S}$ : 'You cook a balanced rice dish, with meat, and veggies, and spices - an aromatic dish. You as the cook were thinking that they may eat well the two days that they are not in school and they say they don't want it and prefer peanut butter and toast.

L: 'That's it [all he wants]. Pizza. Chicken nuggets. Things that I hardly ever have at home. But, I see that he eats it and he only eats a little bit of what I cook, so then I worry and when we go to the market, he begins to pick the things that are in the school. And they're things that he learned from the school.

H1: 'Caucasian people who are overweight like to eat hamburgers and pizzas and drink Pepsi ... Hmong kids too ... They like to eat that .... all the time ... Those foods create fat in their bodies and make them overweight.'

H2: 'The hard part is that Hmong parents eat one thing, Hmong foods, and kids eat American foods; for my family anyways. So you have to bring them with you to shop for their own type of food and they eat only their food. For us older parents, you prepare Hmong foods for yourselves. That's the difficult part but you have to get what they like too so that they eat too.

Parents' uncertainty: about what foods are healthy and unhealthy; cooking techniques; not being the best 'role models'

country which are used - so it is hard for us to know healthy foods.' 1: 'Don't know if the food I give them is healthy. I just give it to them, I don't know what is the benefit in it. There are a lot of things that, we go to the store and we look at it and how do you eat this? Or what could it be? And you smell and "it smell strange".

L2: 'What happens is that, I have eaten salads, that I don't even have any idea how to prepare and are good'

: 'The part about eating boiled vegetables, our children will not eat. Only the older people like us will eat. Really, we don't know either, but white Americans do explain a litle when you get the WIC, right? They tell that you must eat the green vegetables so that there are the green fluids so it can help the body, but our children, some like to eat

$\mathrm{S}$ : 'The ones that I raised I gave them rice, pasta, canjeero - they grew up in a fresh country with fresh air, its food

Structural issues: cost of food, time constraints to prepare foods, transportation costs to obtain foods, seasons, weather, ease of availability, fresh, not put in fridge, meat slaughtered today, milk drawn that day, canjeero mixed that morning is what 1 fed them

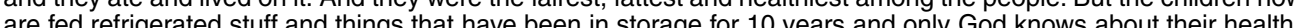
"'Ylou a . . Yingre also have to look at the mave none of it in my house, then I say I better not do it because I do not have money to buy all of that.' 
Parents' approaches to overcome challen

Try to make good choices to buy and prepare children's eating

Cooking or not cooking to children's food preferences

Giving messages to children about eating

Setting expectations and limits

Being good role models

Setting healthy schedules

WIC, Special Supplemental Nutrition Program for Women, Infants, and Children.
$\mathrm{H}$ : 'I think it's important if you know how to do it. But the first, the number one is money. Don't have money. Then, we Hmong, I don't have money. Then I make vegetables and food, I make meat and rice, only. But eating many things don't do. I make one type of food and one type of rice, only. Then if they eat like that, then eat like that only. I don't

$\mathrm{S}$ : 'You know when a house is shared by older people and young consequently you will not cook two meals for the children and the older people. You make food that they can both eat, so it is important'

1: 'So, that is what I did. Before, in my refrigerator, you would never see ... you would see, but it was very rare, the

and eating a little bit, this helps that we are : 'A]t home ice cream and Pepsi is non existent. I don't like

. changes. Pizza is also something that makes kids overweight. We don't buy it either but sometimes kids crave it so when then see it they buy it. Pizza is unhealthy so we don't eat it as

S: 'So whenever she says I don't want this - I would change and order pizza for her; whenever she says I don't want I usually stop making for them. Pizza and other foods - they eat it - I don't think it is healthy but it is something they want. I would be most concerned about their hunger.' doesn't eat, I make his separate. And later, the other kid eats everything.'

$\mathrm{H}$ : 'All you can do is fry or grill meats for them. Young kids will cry about it and you will have to cook it for them. That's all you can do ....

S: 'Now at night, for example after $5 \mathrm{pm}$, heavy food is not good for the little ones ... A small and 'soft' food like vegetables and spinach is what the young and old should eat in the evening.

L: 'My daughter, for example, because she's a little chubby - she wants to be "skinny" ... And I tell her, "If you eat a lot of vegetables instead of eating another pupusa, you will lose more weight." That is how I make her eat vegetables. $H$ : 'About eating it over the limit, like what I had always told my kids, eating it over the limit is also another bad thing. We have to eat it to the point where our body feels comfortable.

S: 'You know they are supposed to drink the juice just once - now my kids I only allow them to have juice once ...' : 'The only day we drink soda is the weekend ... But during the week, we don't have sodas at the table and there are no sodas in the house.

$\mathrm{H}$ : 'When they get older, they're eating hamburgers at school. They eat that at school once or twice. When you eat these foods, it's like our son, when he gets home he eats macaroni and things like that. We don't let him have his way all the time.'

S: 'During the weekends my daughter asks that I make canjeero - in fact she even likes cooking with me. She comes into the kitchen excited - she loves it very much and wants to have it with tea.'

L1: 'For example, in my case, I have stopped buying sweet bread [pan dulce] which is what my nutritionist said. "Don't buy bread because if you and your husband are eating it, your daughter is going to want it too."

2: "And that is what one should be doing. Be an example, serve yourself, vegetables, a plate of vegetables so that they see that you eat them:

H: 'About preparation, we have taught them to eat like us because when kids are old enough to start eating food, we have taught them. When we eat meals and kids don't want to eat vegetables, we teach them that they have to eat vegetables because it helps your body. Don't eat only meat. When kids are younger, it's easier to teach them.

S1: 'But when you cook them a little, that is enough for that day and they eat it and the same for the night and in between the meals if you give them something light ... then their body will get stronger - not fat or thin.'

S2: 'I like to give them breakfast because my child goes to school and I don't like that he leaves home hungry. If he eats at home I would also like that he eat at school as well. Breakfast is important.'

L: 'Because ... I get out late from work. I come home to eat dinner at 6:30 to $7 \mathrm{pm}$. But we all sit down to eat ... because I feel that at least sitting down and eating a little bit, this helps that we are a family and we can have ... little bit of communication ...

H1: 'If he/she is fat, then he/she must not eat, eat so that vegetables and food are eaten at certain times and don't eat too much meat. Don't eat too much rice. Must eat vegetables and eat other things. Fruits and the like.

H2: 'Don't let them be too hungry. If they are too hungry then after they eat they may get stomach problems. ... So they must eat on a consistent schedule and drink enough water. That way they will be healthy.' 
Table 4 Somali (S), Latino (L) and Hmong (H) parents' goals, challenges and strategies for children to be physically active, the Twin Cities, Minnesota, USA, September 2011 through August 2012

\section{Themes}

Parents' goals for their children's physical activity (PA)

\section{Summary/sub-themes}

Supporting PA for their children so they are healthy and happy while ensuring their safety during $P A$

Children's preferences for non-PA and resistance to PA

Parents' uncertainties: not certain how to get children to be active; not knowing how to connect with exercise programmes or gyms

Structural issues: limitations from time, distance, cost, facilities, safety, language, weather, cultural norms

\section{Parent quotes}

S1: 'Yes, even in the cold just dress warm when you are not afraid of them falling in the street. You can walk even in the cold:

S2: 'Some children don't need exercise ... they are running around all day.'

S3: 'Well we used to jump rope, and also play Shabadaan? [jumping squares - a game played by children], but in this country because of the way the buildings are constructed the children cannot make the slightest noise without the neighbours complaining and if they complain three times you will even kicked out of your house. If you are free to pass on these games without getting into trouble that would be good.'

L1: 'We went to the library and I have borrowed music CDs for kids, and they begin to dance right when we get home.'

2: 'What I want to say is that if the kids don't have a lot of activity, how all that processed food they ate, they're not going to get it out? They're not going to get it out because not even in an hour will they burn all those calories.

L3: 'From where I come from, there they didn't buy us toys. There, we entertained ourselves with a stick. We cut a stick of this size, and you sharpened it, and you played with it and hit with it. You hit it with another stick in the air and the stick would fly, like a ball.

H1: 'You have to exercise to stay active. If you don't exercise and stay home only, you will become lazy and unmotivated to do anything.

22: 'Some kids, even if they are fat, exercise so they have tight muscles. Some kids are fat and have loose muscles - they sit around a lot, they exercise for only short amount of time and become out of breath.

S1: 'The children come home tired [from school] they don't even need gym.

S2: 'Yes they are different [boys $v$. girls] - the boys are more troublesome and have more activities and the girls are always calmer.'

L1: '[T]hey are watching too much television. That is what makes it hard for them to be active.'

L2: 'I have to turn off everything that is electronic so that they can sit with me and the family to eat. Because even when they're eating, they're watching TV.

L3: '[B]ecause it's true that one says [to their children], "Go play outside!" and sometimes the kids say, "And why don't you go, mommy?

H1: 'I have a son who doesn't seem to like going to play or exercise or do anything. He keeps going to school and comes back, goes to school and comes back, finishes eating, then watches TV, plays with the computer.'

H2: 'Right now, they also like being on the Internet which greatly decreases their interest in being active.'

S1: 'You cannot discipline your children the way you want. Turning off the TV will be seen as oppressing them. Yesterday you brought them to this country and now you have to be in fear of losing them. S2: 'Yes, safety does prevent them because you have to stay with them; you cannot just let the children go without you, but in Somalia people weren't afraid of them being stolen or beaten or causing them harm:'

3: 'Dances that we used to dance that are cultural heritage that we don't do here but that we used to in our country. So all those we would love for our children to learn and know and do, but it maybe that it is no possible to teach the children here properly.

1: 'Yes, that sometimes one doesn't have the time, in reality. In my case, I go out to work, in the summer, very early in the morning and get home really late at night. I don't have time to take them to do sports ...

2: 'There will always be an excuse. The parents always make an excuse. But the truth is, as parents, you know, "No. Even though it's cold out, let's go outside. Put on your sweaters, and let's go."

. 'One as a parent puts the childcare is closed. So we go to the gym and we ask for a basketball and we play with them, or with football/soccer. And we get them tired. 5-10 min and we go. It's not much, but we're all running.

so forget about it. You can't make them do it'

1: 'We live in cramped spaces - we live in an apartment, there is a family below me, if they jump - "knock, knock!" - "your children have "jumped on me"' [making noise] - "okay sorry"- "please don't call the

2. "It is very good for them to

they come from ome they are really tired; when they come home tired and have to be in school again by 7 in the morning, it is

. against it.' 
Parents' strategies with children's PA
Being good role models

Taking advantage of summer time

Creating indoor activities
L1: 'In the winter, it is the most depressing. There isn't a lot of work, things are super expensive, and no one knows, even if you wanted to, where to go.'

2: '[U]nfortunately one doesn't speak good English and sometimes a Latino parent doesn't talk or doesn't get involved because of the language in the activities. That's why.'

3: 'They [gym staff] discriminate a lot. So, now, your self-esteem lowers. So, you are closing yourself off and like you said, "No. I won't call because .... no."

4: 'T'm going to that free class ... but l'm going to lose $2 \mathrm{~h}$ of work. That's $\$ 12$ of my cheque. You say, "No. I can't go. Better not. You think about that.'

"nother reason why they are overweight is because in this country, when it gets cold, there are not enough places to be active. The kids are always home. The kids don't get a chance to jump around and be active or go

S: 'For me, one of my children I take to gym where he exercises and I pay a monthly fee - withdrawn from my bank. But the others they just play at home - when it is summer I take them out and they play on the swings. 1. 'Oney play ball, and run after each other all day ...

1: 'One as a parent puts themselves to play with them .... we go to the gym and we ask for a basketball and we play with them, or with football/soccer. And we get them tired. 5-10 min and we go. It's not much, but we're all 2. '[M] kids,

My kids, the two younger ones, my daughter of 3 years, and my son of 7 , like I do a lot of Zumba daily, I do a lot of Zumba, and the two little ones, they are always with me. And my daughter, she hears a song or something, and she begins dancing.'

1: '[M]y child is still very young. She's only 4 years old so I exercise, if she sees me exercise, she exercises. She jumps and does jumping jacks and other things.'

H2: 'For my husband and me, we like to play volleyball so he says he wants to teach our daughter how to play volleyball. The sports that we like, we want to teach her and practise with her at home. I want to pass on what we like to her and see what she wants to do too, but we want to teach her that exercise is something very important.'

S: "WW]hen it is summer I take them [children] out and they play on the swings. They play ball, and run after each other all day. But when it is winter, they just stay inside the house, unless I take them outside occasionally.' L: ' $[l] n$ the summer, ... we do make them go outside on their bikes when we can and I take them to the lake to swim.'

$\mathrm{H}$ : 'Take them to play at parks. It seems they are happier and they forgot about their parents not taking them out to play and trying to find other ways to go. If you are consistent with taking your kids out, it seems your kids are not as naughty and listen to you more. It seems like they have more hope in you as parents.'

S: 'Exercise - they get it in the school and during the weekends I give her a small scarf and ask her to dance the buraanbur [traditional dance]. Then she dances ... I saw that she was gaining a little weight and thought of this.'

L: 'It's nice to include them in the activities of one, too ... "What are you doing?", my son says to me, "What are you doing, mommy?" when I'm dancing ... and they get accustomed to it, too.

$\mathrm{H}$ : 'Playing the Wii, your child has one controller and you have one controller. We keep playing until someone wins. I want to win and my child wants to win so we play hard and we are exercising that way... even if you want them to participate, if there isn't anything they're interested in, they won't do it. So if you play games like this, they like it and they want to compete with you and win. This is something easy for them and they'll play it all the time.' 
(like pesticides) in foods. Finally, a few participants described a variety of biological factors that could contribute to children's obesity, such as genetics (parents are fat so children are fat), metabolism (some children eat less and still get fat), digestion (some children digest more or less of the foods they eat) and body composition (some bodies are just fat).

\section{Parents' goals, challenges and approaches to bealthy foods and physical activity}

Parents' perceptions of food and physical activity

Tables 3 and 4 list the parents' perceptions, goals, challenges and approaches. All three groups noted that their everyday traditional foods are healthy, their ceremonial traditional foods are unhealthy if eaten daily and 'American' foods are unhealthy. The traditional daily foods that parents considered healthy were fresh organic vegetables, milk, goat meat and wheat for Somalis; rice and beans for Latinos; and boiled rice, organic vegetables and boiled meat for Hmong. Traditional celebratory foods were generally identified as less healthy, such as Latino tamales, Hmong pig soup, and Somali halwa (dessert) and meat. For Somalis, healthy foods include foods that are purchased, prepared and consumed the same day. The general consensus was that there are important cultural foods that they wish to maintain. However, in their native countries some ceremonial traditional foods were available only at certain times of the year, while they are more readily available and more frequently consumed in the USA.

Parents recognized that PA is important for their children's health, stating that healthy children are inherently physically active and interactive with other people and their environment, while unhealthy children are slow, lazy, weak and inactive. However, the importance of regimented activity differed by community. Somali parents believed that young children are naturally active so do not need organized exercise routines and that older children exercise at school so do not need after-school activities. Latino parents viewed children's physical 'mischief' as normal and establishing an exercise routine (such as afterschool play time) and having family-oriented PA were essential. Hmong parents viewed high levels of children's activity to the point of being naughty as expected and healthy; they also identified the importance of a routine, stating that children are not as naughty when they are consistently active, and stressed the need to guide young children before they make decisions on their own.

Parents' goals for children's eating and physical activity Parents from all three communities shared a main goal about feeding that was to provide healthy food so their children were healthy. They also had two other goals: keep their children happy about food so they would eat and not be malnourished, which might include feeding and eating unhealthy 'American' foods; and teach their 
children to prepare traditional foods to be self-sufficient and maintain their cultural identity (Somali and Hmong). Aiming to keep their children happy, parents experienced a conflict between wanting to offer healthy foods (which children may not want) and buying more unhealthy foods (which children may want), such as 'American' commercial foods and school lunches. Hmong families emphasized teaching boys and girls to cook so that they could be functioning mature adults, while Somalis focused on teaching cooking skills to girls.

Similarly, parents from all three communities shared the same goal of supporting PA for their children so they would be healthy and happy, while ensuring their safety during PA. However, many recognized that purposeful exercise done to promote physical health was not supported by their traditional cultures. Hmong and Somali parents particularly stressed the importance of sweating in being healthy and noted a marked decrease in sweating in the USA from their home countries because of differences in lifestyle and occupational requirements (e.g. walking to the market or farming in their home country).

\section{Parents' challenges to meeting healthy food and physical activity goals}

Parents reported facing similar challenges in their efforts to help their children eat healthy foods and be physically active. Overall, SLH parents tried to achieve a balance between cost, convenience, time, nutritional benefits and family eating habits. The challenges reported by parents included children's desire for 'tasty' foods (salty, fatty and sweet foods), foods that many parents consider 'unhealthy' (American foods like pizzas and hamburgers or traditional ceremonial foods) and a narrow range of specific foods ('picky eaters'). According to a few Hmong parents, their foreign-born children were more receptive to everyday traditional foods compared with their US-born children.

Parents also reported uncertainties about what foods and cooking techniques are healthy and unhealthy - for both traditional and American foods. They also cited structural and environmental factors that influenced their purchasing, preparing and serving healthy foods, such as cost of food, time constraints to prepare food, transportation costs to obtain food, lack of traditional food availability, ease of obtaining and abundance of prepared foods, school food and advertising of unhealthy foods. Somali parents expressed concern about advertisements that expose children to unhealthy American foods, while both Hmong and Latino parents reported concerns about the negative influence of school lunches and the school food environment on their children. In addition, Latino and Hmong parents expressed disappointment with their (or other adult family members') behaviours of not being the best 'role models'.

Similarly, SLH parents faced challenges in achieving balance for PA, including cost, convenience, time, transportation and family habits. Some expressed common concerns with children's preferences for sedentary activities (e.g. watching television or playing video games) which, when coupled with children's resistance to PA, were difficult for parents to overcome. They also expressed struggles, including uncertainties about how to support children's exercise, given their own lack of personal exercise, their lack of knowledge about exercise programmes and organizations, their busy lives and key structural constraints. Parents struggled to find time for regular family exercise, given work, school or day care schedules, being tired after work and school, and having to attend to extended family needs especially on the weekends. They also cited significant structural and environmental issues as obstacles to exercising, including neighbourhood safety, winter weather causing discomfort and illness, and playing inside in small homes because of space constraints, leading to noise and possible eviction notices. Challenges in accessing community organizations with exercise programmes because of high cost, distance and language barriers were also reported. In addition, Somali parents found most PA programmes unacceptable because of women's revealing clothing and not being separated by gender. Latino parents had experiences with feeling unwelcomed and even discriminated against at fitness centres.

\section{Parents' approaches to overcoming challenges}

Parents utilized various approaches to ensure their children ate healthy foods and were physically active. Generally, all parents purchased and prepared foods they considered healthy and avoided foods they considered unhealthy. In addition to cultural variations about which foods or approaches were considered healthy, a few Somali parents mentioned trying to cook traditional foods in healthy ways; Latino parents emphasized the importance of having regular family meals; and Hmong parents stressed serving a variety of foods and colours, as well as valuing the knowledge they gained from doctors (e.g. eat lean meats and avoid fatty pork; boil rather than fry foods). Overall, parents described striving to serve healthy, traditional foods cooked in a variety of ways that their children would enjoy.

To accommodate their children's food preferences, parents described two distinct parenting approaches: they either (i) prepared multiple meals to satisfy individual preferences to ensure their children were not hungry or (ii) prepared one meal for everyone in the family. Most Hmong parents mentioned catering to their children's desires including purchasing a variety of foods and/or cooking foods multiple ways (e.g. an American meal for children and a Hmong meal for adults); Somali and Latino families reported using either approach.

Parents from each community used various feeding practices and food-related messages to encourage their children to eat, such as setting expectations and limits, although different approaches were emphasized across ethnic groups. Somali parents described encouraging their children to finish their food by telling them that the last piece of the food has the 'most reward', referring to 
religious context of being rewarded for cleaning one's plate. Latino parents stressed the importance of trying new foods, giving warnings that overeating will lead to obesity and avoiding offering food as a reward for good behaviours. Hmong parents commonly told their children to eat until they are 'stuffed'; however, some Hmong parents also set limits on 'bad' foods.

Parents stressed the importance of being good role models for preparing and eating healthy foods and setting food schedules, although they had different emphases. Latino and Hmong parents wanted their children to eat scheduled meals and not snack repeatedly throughout the day. Latino and Somali parents particularly stressed the importance of family meals because it reinforces the meaning of family. In addition, parents acknowledged their role modelling as a strategy to help their children eat healthily and be physically active, although they recognized the challenges and limitations of being effective role models, given their own behaviours.

Regarding their children's PA, parents had similar strategies with slight differences across the three communities. They mentioned the importance role modelling PA and the role of others (e.g. extended family members) who are often involved in raising their children and their influence on their children's behaviours. Given limited indoor space and severe winter weather in Minnesota, parents from different ethnic groups creatively made do with what they had: walking up and down hallways and stairways in apartment buildings, setting up space in basements, buying interactive video games, and dancing to videos and music. While the summer provided more opportunities for low-cost activities like outdoor play, parents expressed their desire to know more about nonexpensive places for children's activities during the winter, such as low-priced neighbourhood programmes and local gymnasiums. They were generally hopeful about schools providing exercise for their children, with Somalis assuming that schools do so during the school day, while Latinos were critical of schools for not supporting afterschool activities. Hmong and Latino parents expressed valuing and enjoying activities with their children and some Somali parents seemed to like the idea of exercising at a gender-divided gym while their children are occupied.

\section{Parents' programmatic suggestions}

Table 5 describes the parents' suggestions for programmes to help them improve their families' healthful eating and PA. Parents across all three communities voiced an interest in cooking classes for adults and children to gain new knowledge about identifying and cooking healthy foods, learning about which American foods are healthy/unhealthy and shopping for healthy foods on a budget. Participants wanted programmes that are free, easy to access (or with free transportation), provide childcare or children's programming, and are offered at convenient times to accommodate family schedules. Latino and Hmong parents wanted programmes to incorporate recipes for quick, tasty and healthy meals, and healthy portion sizes. Latino parents were also interested in learning more about food preservation and meal planning, age-appropriate healthy body size, and becoming knowledgeable about and involved in improving the quality of school food programmes. Hmong parents were interested in learning about age-appropriate healthy food choices for children, identifying healthy options at fast-food restaurants, and understanding the medical risks of unhealthy diets for both obesity and eating disorder prevention. Somali parents specified that religious requirements (e.g. no pork) needed to be observed in any programme.

Participants from all three ethnic communities wanted convenient access to open spaces for exercise, particularly large indoor spaces in which their children could run and play. Hmong and Latino parents welcomed family-based exercise activities, while Somali participants desired separate exercise spaces for men and women. Latino parents wanted more information about local free or low-cost programmes, particularly where families could exercise together and where peers could motivate children to be physically active. All parents wanted to stay warm in the winter, with Latinos expressing some desire to be active outside in the winter, including participating in winter sports. Hmong parents mentioned the possibility of combining cooking and exercising programmes. While not a requirement, Somali and Hmong parents preferred an exercise instructor of their ethnicity; for Somalis, this could be combined with teaching traditional cultural activities such as dances, storytelling and games.

\section{Discussion}

The current CBPR qualitative study identified SLH parents' perceptions about children's weight, causes of childhood obesity, parent's goals to raising healthy-weight children, challenges to dietary and PA goals, and approaches to addressing these challenges. The findings indicate that immigrant parents aim to raise healthy and happy children in the USA by balancing their understanding of obesity, eating and PA with their economic and social challenges, while attempting to maintain their cultural identity. Overall, there were more similarities than differences in SLH parents' experiences of feeding their children and supporting their PA, which emphasizes the common social, environmental, structural and economic factors of living in the USA ${ }^{(37)}$. Similar results as in our study emerged in previous qualitative studies conducted with immigrant populations (e.g. Somali, Mexican and Cambodian) $)^{(34,37)}$. The similarities shared by these communities about raising healthy children around their dietary intake and PA indicate that a core intervention programme designed for immigrant parents could be relevant to multiple ethnic groups, with adaptations for language and culture. 
Although the majority of SLH parents reported that a child's weight is not necessarily health-based and children can be healthy at both ends of the weight range, the majority of participants indicated that being in the middle of the weight range is likely to be healthier. This finding is consistent with other qualitative studies among immigrant groups that found a child's health is defined not by weight but by appearance such as energy level, skin and hair appearance, and emotional health, such as happiness ${ }^{(30,32)}$. These parents were generally more concerned about their children not becoming malnourished than not becoming obese. Thus, the parents were willing to fulfil their children's preference for 'unhealthy American' foods, contrary to parents' desire to feed them their everyday traditional foods. In a recent study of parent feeding styles among low-income first-generation Hispanic mothers, compared with USA-born mothers, immigrant mothers more frequently pressured their children to eat, used food as a reward and limited intake of non-healthy foods ${ }^{(50)}$. Similarly in a previous study, Somali parents favoured large portion sizes and a larger body size as a sign of better health ${ }^{(37)}$. Variation in feeding styles and concern about child malnutrition may reflect cultural norms and past experiences around food, especially food insecurity and immigration status, which may have been true for some participants in the present study ${ }^{(51)}$. However, our study did not assess the participants' resettlement process prior to arrival in the USA. Since past food experiences may be integral factors in shaping immigrant families' behaviours about feeding children, future studies should explore and address these factors.

The challenges reported by these parents present opportunities for interventions to improve families' dietary and PA behaviours. One of the identified challenges was the generational differences in food preference, as older family members prefer more traditional foods than younger members, and as some (perhaps foreign-born) children prefer traditional foods compared with other (particularly American-born) children. The diverse eating patterns among family members may reflect the interplay of multiple factors, including structural issues, desire for cultural preservation, school food, the local food environment and the media ${ }^{(52,53)}$. According to findings of other qualitative studies with immigrant populations, the preference for 'American' foods by children and adolescents may be the result of the children's reactions to their families' desire and control to maintain traditional food ways $^{(37)}$. Future studies should assess intergenerational dynamics with respect to eating and PA, and future healthy-weight programmes for immigrant communities should include intergenerational communication and interaction as an integral component ${ }^{(54)}$.

Other challenges reported by SLH parents that were found in other qualitative studies were lack of knowledge about what constitutes healthy foods ${ }^{(55)}$, especially American foods preferred by their children ${ }^{(37,52)}$, unfamiliarity with certain local fruits and vegetables and ways to prepare them, and lack of control of children's eating habits. Overall, parents expressed limited knowledge of the local food environment, their belief that American foods are unhealthy and traditional foods are healthy, and their desire to pass on traditional foods and eating habits to their children. Our findings suggest that many immigrant families have had limited exposure to American foods, therefore they may be unaware of a range of 'healthy' American foods. A study by Arcan et al. found that Somali adolescents consumed fast food almost daily ${ }^{(8)}$. Fast-food and other low-cost food consumption is often linked to lower socio-economic status and overall neighbourhood food availability ${ }^{(56-59)}$, and in our study cost of foods was reported as one of the challenges preventing parents from feeding their families healthier foods. When immigrant families first arrive to the USA, their limited financial resources and lack of familiarity with local healthy foods may prohibit them from purchasing healthy options, thus exposing them predominantly to the taste and familiarity of convenient foods. As Lee et al. posited, a longer stay in the USA was strongly correlated with negative dietary changes among adult immigrants. Further, both length of stay and dietary changes were strong predictors of negative self-reported health status, indicating the decline of diet quality may be a factor in the pathway towards declining health ${ }^{(22)}$. Collectively, these findings present a great opportunity for nutrition education, especially soon after arrival to the USA, to introduce immigrant families to healthy American foods and ways to obtain and prepare them on a limited budget.

To maintain their cultural identity and feel connected with their past while in the host country, immigrant families participate in ethnic social occasions that involve sharing food, especially 'ceremonial foods' that may be high in energy, fats and refined carbohydrates. The parents recognized that these foods, which were previously consumed only on special occasions, are now more readily available in the USA and are increasingly becoming a part of everyday diet $^{(60)}$. A previous focus group study among Somali parents indicated lower intakes of fruits and vegetables and higher intakes of meat and pasta, reflecting their perception that meat consumption was associated with higher social status $^{(61)}$. Recognizing the need for social connectedness and the increasing role of ceremonial foods in immigrant diets, nutrition interventions can incorporate tips on healthful choices and cooking methods of these foods.

The need for social connectedness among immigrant groups was also expressed when SLH parents recommended that future programmes promoting PA are familyand community-focused. Although all participants agreed that PA was important in achieving and maintaining health, they cited challenges to PA that are common to other immigrant groups, including socio-economic position and environmental and structural factors ${ }^{(33,34,62)}$. Moreover, the way PA was conceptualized and practised 
by some immigrant groups might pose an additional challenge to being physically active in the host country ${ }^{(34,63)}$. As physical labour and sweating were an integral part of their daily work routines, many immigrant groups are not accustomed to recreational exercise and do not feel as if they are physically active without sweating ${ }^{(34)}$. In addition, as expressed by Somali participants, moral and cultural norms about gender differences in PA practices and prohibitions against exercising in public should be addressed in order to increase participation and ensure sustainability of behaviours ${ }^{(64)}$. An example of a culturally tailored programme that respected gender differences was the development of a swimming programme for Somali women in Seattle ${ }^{(65)}$.

Study limitations include the convenience sample of focus group participants that limits the generalizability of the findings; the qualitative design that prevents quantification of differences across ethnic groups; and lack of measurement of acculturation that prevents discussion about the families' acculturative change. Lastly, although the inclusion of immigrant participants from three distinct ethnic communities makes the sample heterogeneous, the findings of the study may not be generalizable as they reflect the influence of the social norms of the local environment on the participants' food- and PA-related attitudes and behaviours that may be different for people living in different geographic areas.

\section{Conclusions and implications}

The study's findings indicate that immigrant parents aim to raise healthy-weight children by providing healthy foods and PA for their children. However, they face multiple challenges that require parents' adjustment and negotiation between the push of dominant culture, new familial and generational dynamics, and preservation or development of their ethnic community identity. These study results will guide the design of programmatic interventions with strong community participation, following the principles of CBPR, in order to maximize the programme's effectiveness. Future programmes should elicit participants' goals, build upon common goals, acknowledge and attempt to address the challenges that impair parents' abilities to meet their goals, and focus on building parents' knowledge, skills and strategies needed to address the challenges. Future qualitative research should extensively measure level of acculturation for each ethnic community to address the participants' specific needs more effectively. While logistical issues of language, location, food preferences and activity preferences have to be addressed, programmes that draw people from different ethnic groups together could allow for successful learning and sharing between groups, strengthen relationships between people, and empower them to form alliances that could address larger societal issues, such as safe neighbourhoods.

\section{Acknowledgements}

Acknowledgements: The authors extend their appreciation to all community members who participated in the focus groups. They extend special appreciation to Hodan Dualeh, Warda Geele, Luis E. Ortega, Mai See Thao and Charles Vang, SoLaHmo members, for their participation in all phases of the project. Financial support: This work was supported by the UCare Foundation (grant number 2011-09R). The UCare Foundation had no role in the design, analysis or writing of this article. Conflict of interest: None. Authorship: At the time of the study, C.A. was a Research Associate at the Division of Epidemiology and Community Health, School of Public Health, University of Minnesota, Minneapolis. C.A. was the lead author and participated in the study development, analysis and interpretation of the results. K.A.C.-P. participated in the study development, analysis and interpretation of the results, and critically reviewed and edited the manuscript. S.P. advised on the CBPR approach, participated in the study development, analysis and interpretation of the results and critically reviewed and edited the manuscript. M.R.-L. conducted, transcribed and translated the focus groups, participated in data analysis and interpretation of the results, and reviewed the manuscript. M.B.X. conducted, transcribed and translated the focus groups, participated in data analysis and interpretation of the results, and reviewed the manuscript. Ethics of buman subject participation: This study was conducted according to the guidelines laid down in the Declaration of Helsinki and all procedures involving human subjects/patients were approved by the Institutional Review Board of the University of Minnesota. Written informed consent was obtained from all subjects.

\section{References}

1. Gambino C, Trevelyan E \& Fitzwater J (2014) The foreignborn population from Africa: 2008-2012. American Community Survey Briefs no. ACSBR/12-16. http://www.census. gov/content/dam/Census/library/publications/2014/acs/ acsbr12-16.pdf (accessed February 2016).

2. US Department of Commerce, US Census Bureau (2013) Asians fastest-growing race or ethnic group in 2012, Census Bureau reports. Release no. CB13-112. http://www.census. gov/newsroom/releases/archives/population/cb13-112.html (accessed April 2016).

3. Camerota SA (2012) Immigrants in the United States, 2010: a profile of America's foreign-born population. http://www. cis.org/sites/cis.org/files/articles/2012/immigrants-in-theunited-states-2012.pdf (accessed April 2016).

4. Minnesota Department of Health, WIC Program and CSFP (2015) Obesity and Overweight Status in Minnesota WIC Children Fact Sheet, 2015. St. Paul, MN: Minnesota Department of Health; available at http://www.health.state. mn.us/wic/localagency/reports/wtstatus/info/factsheet0915 child.pdf

5. Walker P \& Barnett E (editors) (2007) An introduction to the field of refugee and immigrant healthcare. In Immigrant Health, pp. 1-9. Philadelphia, PA: Elsevier Press. 
6. Flegal KM, Kruszon-Moran D, Carroll MD et al. (2016) Trends in obesity among adults in the United States, 2005 to 2014. JAMA 315, 2284-2291.

7. Spencer N, Thanh TM \& Louise S (2013) Low income/socioeconomic status in early childhood and physical health in later childhood/adolescence: a systematic review. Matern Child Health J 17, 424-431.

8. Arcan C, Larson N, Bauer K et al. (2014) Dietary and weightrelated behaviors and body mass index among Hispanic, Hmong, Somali, and White adolescents. J Acad Nutr Diet 114, 375-383.

9. Dey AN \& Lucas JW (2006) Physical and mental health characteristics of US- and foreign-born adults: United States, 1998-2003. Adv Data issue 369, 1-19.

10. Goel MS, McCarthy EP, Phillips RS et al. (2004) Obesity among US immigrant subgroups by duration of residence. JAMA 292, 2860-2867.

11. Koya DL \& Egede LE (2007) Association between length of residence and cardiovascular disease risk factors among an ethnically diverse group of United States immigrants. J Gen Intern Med 22, 841-846.

12. Creatore MI, Moineddin R, Booth G et al. (2010) Age- and sex-related prevalence of diabetes mellitus among immigrants to Ontario, Canada. CMAJ 182, 781-789.

13. Lear SA, Humphries KH, Hage-Moussa S et al. (2009) Immigration presents a potential increased risk for atherosclerosis. Atherosclerosis 205, 584-589.

14. Perera S, Gavian M, Frazier P et al. (2013) A longitudinal study of demographic factors associated with stressors and symptoms in African refugees. Am J Orthopsychiatry 83, 472-482.

15. Lytle LA, Hearst MO, Fulkerson J et al. (2011) Examining the relationships between family meal practices, family stressors, and the weight of youth in the family. Ann Behav Med 41, 353-362.

16. Fulkerson JA, Kubik MY, Story M et al. (2009) Are there nutritional and other benefits associated with family meals among at-risk youth? J Adolesc Health 45, 389-395.

17. Brewer M \& Kimbro RT (2014) Neighborhood context and immigrant children's physical activity. Soc Sci Med 116, $1-9$.

18. Gordon-Larsen P, McMurray RG \& Popkin BM (2000) Determinants of adolescent physical activity and inactivity patterns. Pediatrics 105, E83.

19. Gordon-Larsen P, Nelson MC, Page P et al. (2006) Inequality in the built environment underlies key health disparities in physical activity and obesity. Pediatrics 117, 417-424.

20. Perez LG, Slymen DJ, Sallis JF et al. (2016) Interactions between individual and perceived environmental factors on Latinas' physical activity. J Public Health (Oxf) 39, e10-e18.

21. Acevedo-Garcia D, Bates LM, Osypuk TL et al. (2010) The effect of immigrant generation and duration on selfrated health among US adults 2003-2007. Soc Sci Med 71, $1161-1172$

22. Lee S, O'Neill AH, Ihara ES et al. (2013) Change in selfreported health status among immigrants in the United States: associations with measures of acculturation. PLoS One 8, e76494.

23. Akresh IR (2007) Dietary assimilation and health among Hispanic immigrants to the United States. J Health Soc Behav 48, 404-417.

24. Patrick H \& Nicklas TA (2005) A review of family and social determinants of children's eating patterns and diet quality. J Am Coll Nutr 24, 83-92.

25. Gillman MW, Rifas-Shiman SL, Frazier AL et al. (2000) Family dinner and diet quality among older children and adolescents. Arch Fam Med 9, 235-240.

26. Thompson OM, Ballew C, Resnicow K et al. (2006) Dietary pattern as a predictor of change in BMI z-score among girls. Int J Obes (Lond) 30, 176-182.
27. Kral TV \& Rauh EM (2010) Eating behaviors of children in the context of their family environment. Physiol Behav 100, $567-573$

28. Arcan C, Neumark-Sztainer D, Hannan P et al. (2007) Parental eating behaviours, home food environment and adolescent intakes of fruits, vegetables and dairy foods: longitudinal findings from Project EAT. Public Health Nutr 10, $1257-1265$.

29. Savage JS, Fisher JO \& Birch LL (2007) Parental influence on eating behavior: conception to adolescence. J Law Med Ethics 35, 22-34.

30. Crawford PB, Gosliner W, Anderson C et al. (2004) Counseling Latina mothers of preschool children about weight issues: suggestions for a new framework. J Am Diet Assoc 104, 387-394.

31. Head BJ, Barr KL \& Baker SK (2011) Mexican American parents' perceptions of childhood risk factors for type 2 diabetes. J Sch Nurs 27, 51-60.

32. Pham KL, Harrison GG \& Kagawa-Singer M (2007) Perceptions of diet and physical activity among California Hmong adults and youths. Prev Chronic Dis 4, A93.

33. Wieland ML, Weis JA, Palmer T et al. (2012) Physical activity and nutrition among immigrant and refugee women: a community-based participatory research approach. Womens Health Issues 22, e225-e232.

34. Wieland ML, Tiedje K, Meiers SJ et al. (2015) Perspectives on physical activity among immigrants and refugees to a small urban community in Minnesota. J Immigr Minor Health 17, 263-275.

35. Franzen-Castle L \& Smith C (2014) Environmental, personal, and behavioral influences on BMI and acculturation of second generation Hmong Children. Matern Child Health J 18, 73-89.

36. Franzen L \& Smith C (2010) Food system access, shopping behavior, and influences on purchasing groceries in adult Hmong living in Minnesota. Am J Health Promot 24, 396-409.

37. Tiedje K, Wieland ML, Meiers SJ et al. (2014) A focus group study of healthy eating knowledge, practices, and barriers among adult and adolescent immigrants and refugees in the United States. Int J Behav Nutr Phys Act 11, 63.

38. Bayles B (2010) Perceptions of childhood obesity on the Texas-Mexico border. Public Health Nurs 27, 320-328.

39. Ward CL (2008) Parental perceptions of childhood overweight in the Mexican American population: an integrative review. J Sch Nurs 24, 407-416.

40. Ayala GX, Ibarra L, Binggeli-Vallarta A et al. (2015) Our Choice/Nuestra Opción: the Imperial County, California, Childhood Obesity Research Demonstration study (CA-CORD). Child Obes 11, 37-47.

41. Dankwa-Mullan I, Rhee KB, Williams K et al. (2010) The science of eliminating health disparities: summary and analysis of the NIH summit recommendations. Am J Public Health 100, Suppl. 1, S12-S18.

42. Panapasa S, Jackson J, Caldwell C et al. (2012) Communitybased participatory research approach to evidence-based research: lessons from the Pacific Islander American Health Study. Prog Community Health Partnersh 6, 53-58.

43. Minkler M \& Wallerstein N (2009) Community-based participatory research for health: from process to outcomes. Health Promot Pract 10, 317-318.

44. Macaulay AC, Commanda LE, Freeman WL et al. (1999) Participatory research maximises community and lay involvement. North American Primary Care Research Group. BMJ 319, 774-778.

45. Israel BA, Schulz AJ, Parker EA et al. (1998) Review of community-based research: assessing partnership approaches to improve public health. Annu Rev Public Health 19, 173-202. 
46. Carlsen B \& Glenton C (2011) What about N? A methodological study of sample-size reporting in focus group studies. BMC Med Res Methodol 11, 26.

47. Jackson SF (2008) A participatory group process to analyze qualitative data. Prog Community Health Partnersh 2, $161-170$

48. Morgan DL \& Krueger RA (1998) The Focus Group Kit. Thousand Oaks, CA: SAGE Publications, Inc.

49. Vaismoradi M, Turunen H \& Bondas T (2013) Content analysis and thematic analysis: implications for conducting a qualitative descriptive study. Nurs Health Sci 15, 398-405.

50. Power TG, O'Connor TM, Orlet Fisher J et al. (2015) Obesity risk in children: the role of acculturation in the feeding practices and styles of low-income Hispanic families. Child Obes 11, 715-721.

51. Peterman JN, Wilde PE, Liang S et al. (2010) Relationship between past food deprivation and current dietary practices and weight status among Cambodian refugee women in Lowell, MA. Am J Public Health 100, 1930-1937.

52. Franzen L \& Smith C (2009) Acculturation and environmental change impacts dietary habits among adult Hmong. Appetite 52, 173-183.

53. Mulasi-Pokhriyal U \& Smith C (2010) Assessing body image issues and body satisfaction/dissatisfaction among Hmong American children 9-18 years of age using mixed methodology. Body Image 7, 341-348.

54. Rhodes K, Chan F, Prichard I et al. (2016) Intergenerational transmission of dietary behaviours: a qualitative study of Anglo-Australian, Chinese-Australian and Italian-Australian three-generation families. Appetite 103, 309-317.

55. Head BJ, Barr KL \& Baker SK (2011) Mexican American parents' perceptions of childhood risk factors for type 2 diabetes. J Sch Nurs 27, 51-60.
56. Watts AW, Mason SM, Loth K et al. (2016) Socioeconomic differences in overweight and weight-related behaviors across adolescence and young adulthood: 10-year longitudinal findings from Project EAT. Prev Med 87, 194-199.

57. Svastisalee CM, Holstein BE \& Due P (2012) Fruit and vegetable intake in adolescents: association with socioeconomic status and exposure to supermarkets and fast food outlets. J Nutr Metab 2012, 185484.

58. Richardson AS, Meyer KA, Howard AG et al. (2014) Neighborhood socioeconomic status and food environment: a 20-year longitudinal latent class analysis among CARDIA participants. Health Place 30, 145-153.

59. Cook WK, Tseng W, Tam C et al. (2017) Ethnic-group socioeconomic status as an indicator of community-level disadvantage: a study of overweight/obesity in Asian American adolescents. Soc Sci Med 184, 15-22.

60. Azar KM, Chen E, Holland AT et al. (2013) Festival foods in the immigrant diet. J Immigr Minor Health 15, 953-960.

61. McEwen A, Straus L \& Croker H (2009) Dietary beliefs and behaviour of a UK Somali population. J Hum Nutr Diet 22, 116-121.

62. Gidlow C, Johnston L, Crone D et al. (2006) A systematic review of the relationship between socio-economic position and physical activity. Health Educ J 71, 338-367.

63. Rothe E, Holt C, Kuhn C et al. (2010) Barriers to outdoor physical activity in wintertime among Somali youth. J Immigr Minor Health 12, 726-736.

64. Devlin JT, Dhalac D, Suldan AA et al. (2012) Determinants of physical activity among Somali women living in Maine. J Immigr Minor Health 14, 300-306.

65. Moore E, Ali M, Graham E et al. (2010) Responding to a request: gender-exclusive swims in a Somali community. Public Health Rep 125, 137-140. 